\title{
Evaluation and introduction of integrated arable farming in practice
}

\author{
F.G. WIJNANDS
}

Research Station for Arable Farming and Field Production of Vegetables, P.O. Box 430, NL 8200 AK, Lelystad, Netherlands

Received 28 November 1991; accepted 31 March 1992

\begin{abstract}
A four-year project to evaluate and introduce integrated arable farming systems (IFS) in practice is presented. The project comprises the testing of IFS prototypes that have been developed at experimental farms by a group of pilot farms and the introduction of IFS in the farming community, mainly by the establishment of a network of study groups. To support these main activities, training programmes and courses are organized for advisers, teachers and farmers. Preliminary results of the pilot farms show perspectives of IFS to considerably reduce pesticide and nutrient inputs under varying farm and management conditions. A broader adoption of IFS seems until now more hampered by social than technological causes, notably by the lack of motivation and cooperation of extensionists and farmers.
\end{abstract}

Keywords: pesticides, conversion, integrated farming systems, pilot farms, environment, extension, fertilizers, arable farming, on-farm research

\section{Introduction}

In the Netherlands, prototypes of integrated arable farming systems (IFS) are developed regionally at three experimental farms (Wijnands \& Vereijken, 1992). IFS aims at serving both ecologic and economic objectives by substituting potentially noxious agrochemical inputs by both agricultural and ecological knowledge, labour and nonchemical husbandry techniques (Vereijken, 1992). At the experimental farms considerable reduction in pesticide and nutrient inputs are achieved with economic results similar to the conventional systems (Wijnands \& Vereijken, 1992).

In the agricultural policy of the Netherlands, integrated production is considered as a major tool to reduce the adverse effects of high pesticide and nutrient inputs (Anonymous, 1990; Anonymous, 1991). It is aimed at $30 \%$ of the farmers/growers adopting integrated production methods by 1994 and $100 \%$ by the year 2000 (Anonymous, 1990). Consequently, the challenge of the nineties in the Netherlands is to succesfully implement the IFS approach.

The available IFS prototypes consist of a coherent set of methods and techniques or substrategies concerning crop rotation, fertilization (Verelijken, 1990), crop protection (Vereijken, 1989a) and the growing of specific crops (Vereijken \& Van Loon, 


\section{F.G. WIJNANDS}

1991; Vereijken, 1989b; Wijnands \& Vereijken, 1989). Although these prototypes are elaborated under experimental farm conditions (Wijnands \& Vereijken, 1992), it is still not known to what extent they are interesting and feasible in practice, since the management factor is more or less excluded at the experimental farms and these only reflect a limited range of conditions. For this reason, testing of the experimental prototypes with a pilot group of farmers is indispensable to reveal the potential of IFS in practice in terms of performance and feasibility under varying soil, farm and management conditions and to acquire the necessary knowledge on which regionspecific, safe and generally applicable variants of IFS should be based (Vereijken, 1992). A large-scale introduction of IFS can only be succesful if this, region-specific knowledge is available and the total farming community (farmers, advisors, teachers, industry etc.) is sufficiently motivated for and, preferably by practical experience, familiar with (elements of) IFS.

Consequently, a cooperative project (1990-1993) of the agricultural extension service and several research institutes has been set up to initiate the large-scale introduction of IFS. The first activity concerns the establishment of a nation-wide network of pilot farms to test the IFS prototypes. The second activity concerns the introduction of IFS in the farming community, mainly through the establishment of a

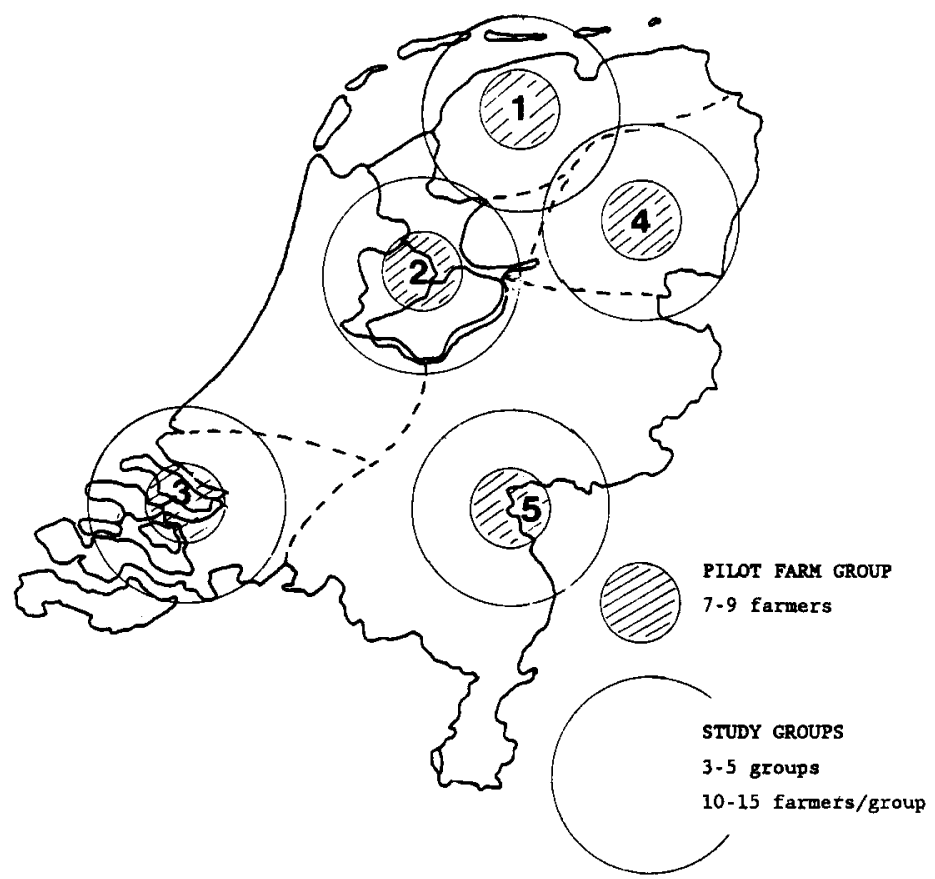

Fig. 1. Main arable production areas with major crops: overview of set-up of project.

1 = Northern Clay $(\mathrm{NC})$ : seed potato

2 = Central Clay $(\mathrm{CC})$ : ware potato

3 = Southwestern Clay (SWC): diversified crop rotations

$4=$ Northeastern Sand (NES): potato for starch production

$5=$ Southeastern Sand (SES): root crops and vegetables for cannery 
network of farmers' study groups. To support this, training programmes and courses are organized for advisors, teachers and farmers.

\section{Methodology}

\section{Testing of prototypes on pilot farms}

In order to obtain sufficient diversity of soil, farm and management conditions, five pilot groups of about eight farms have been started in the major arable production areas of the Netherlands (Figure 1). In each region an extension officer, trained in IFS, is appointed for the project period to support the adoption of IFS on the pilot farms and to introduce IFS into the farming community. They are technically supported by the Research Station for Arable Farming and Field Production of Vegetables (PAGV), which also coordinates the research programme that evaluates the performance of the pilot farms. At monthly meetings of the project team the ongoing farm and research activities are discussed and coordinated (Table 1).

\section{Selection of pilot farms}

Pilot farms have been selected on the following criteria:

- acceptance of a package of minimum agronomic demands for IFS (Table 2);

- representativeness for the regional conditions;

- availability of technical data from the recent past;

- willingness to record all required data during the project period;

- additional criteria such as farm viability, demonstrative value, participation in farmers' organizations, etc.

\section{Conversion plan, contract}

The starting position of every selected farm is assessed through a detailed registration of the management in the three years preceeding the project period (19871989). After analysis of these data (strong and weak points in the farm management so far), and based on the IFS agronomical demands (Table 2), a farm-specific conversion plan is made in cooperation between farmer and extension officer. It contains a detailed planning of farming activities (crop rotation, fertilization, crop protection and mechanization) as a basis for the actual cropping programmes (chronological list of measures and criteria per crop) for the first season. The conversion plan also documents the initial constraints. The farmers commit themselves through a contract to this fundamental and planned conversion.

\section{Adoption, implementation and annual adjustment}

As on the experimental farms, IFS on the pilot farms should be carried out consistently. The adoption and implementation of IFS, based on the farmspecific conversion plan, is supported by the specialized extension officer, who visits the partici- 


\section{F.G. WIJNANDS}

Table 1. Evaluation and introduction of IFS in practice.

\begin{tabular}{lll}
\hline & Test of IFS prototypes on pilot farms & $\begin{array}{l}\text { Introduction of IFS into the farming } \\
\text { community }\end{array}$ \\
Objectives & $-\begin{array}{l}\text { evaluate performance and feasibility } \\
\text { of IFS in practice } \\
\text { elaborate region-specific, generally } \\
\text { applicable variants of IFS }\end{array}$ & $\begin{array}{c}\text { transfer of knowledge and practi- } \\
\text { cal expertise } \\
\text { evaluate interest, adoption and } \\
\text { constraints }\end{array}$ \\
Set-up & $\begin{array}{l}38 \text { pilot farms in five regional groups } \\
\text { (Figure 1), adoption of IFS supported } \\
\text { by five specialized extension officers }\end{array}$ & $\begin{array}{l}20-25 \text { study groups in five regions } \\
\text { (Figure 1); organization of courses, } \\
\text { seminars and meetings }\end{array}$ \\
& $\quad$ AES)
\end{tabular}

Table 2. Agronomic demands for IFS pilot farms.

\section{Crop rotation}

- multi-functional to support the crop protection and nutrient management strategies.

\section{Nutrient management}

- $\mathrm{P} / \mathrm{K}$ input in balance with farm $\mathrm{P} / \mathrm{K}$ output, as related to the soil fertility status;

- $\mathrm{P} / \mathrm{K}$ input based on organic manure, supplemented by mineral fertilizers;

- organic manure use aimed at maximum crop uptake and minimum emission losses by appropriate dosing, timing and application technique;

- optimum use of green manures as catch crops for $\mathrm{N}$ to prevent leaching losses;

- moderate $\mathrm{N}$ fertilization to support crop resistance against diseases, pests and lodging, to produce high quality products and to reduce $\mathrm{N}$ losses after harvest. $\mathrm{N}$ fertilization level adjusted for $\mathrm{N}$ from organic sources (manures, crop residues).

Crop protection

- maximum prevention based on broad-resistant/tolerant cultivars supported by seed treatments;

- use of monitoring and guidance systems for pest, disease and weed control;

- mechanical weed control, supplemented by band spraying;

- full-width chemical control of pests and diseases only as last resort, based on economic criteria;

- progressive exclusion of persistent and mobile pesticides, starting from an up-dated 'black list' for water-collecting areas.

pating farms frequently. The regional pilot groups also meet regularly, since an intensive interaction between the participants is indispensable for a succesful adoption of IFS. During the growing season, technical matters are discussed on the farms. In winter the growing season is evaluated and new plans are made. The cropping 
plans are adjusted annually, based on crop-oriented evaluation meetings of the project team (attented by crop experts), the results of the evaluative research and the winter meetings of the pilot groups. This is included in the bilateral communication between farmer and extension officer.

\section{Evaluation of performance and feasibility; research programme}

The evaluation of the performance of pilot farms concerns agronomic, environmental and economic aspects (Table 3). It requires a thorough analysis of the starting position of the participating farms. Detailed technical data and assessments of soil fertility and occurence of soil-borne pests and pathogens are available for the three years preceeding the project. As an actual reference, data are used from the national economic survey of arable farms. From these farms, major in- and outputs are available. During the project, all in- and outputs, cropping measures and other relevant technical data are recorded by the participating farmers. All data are stored in a database which enables efficient analysis by different research groups. These data are completed with more qualitative evaluation reports by the specialized extension officers.

The agronomic and environmental performance of the pilot farms is primarily evaluated by our research station. Important agronomic criteria (Table 3) are: how and to what extent are IFS techniques adopted and how sustainable is the IFS practice. This last point concerns the soil fertility, structure and biology (including soilborne pest, pathogens and weeds) and the quality of the produce. Obviously, sustainability can only be assessed on the long term. However, there may be some indications gained at an earlier stage. The population of soil-borne pests is followed in detail in the Northeastern Sand region, where the situation is most problematic and the IFS approach is aimed at eliminating the use of nematicides (Wijnands \& Vereijken, 1992). The evaluation of the environmental impact of IFS focuses on the use of pesticides and the emissions of $\mathrm{N}$ to ground- or surface water. These emissions are measured on a selected number of farms and fields. To enable generalization of the results, additional assessments are performed of the $\mathrm{N}$ status of the soil, the $\mathrm{N}$ turnover in green manure crops and crop residues, groundwater level fluctuations, etc.

The economic performance of the pilot farms is evaluated by LEI-DLO, based on annual economic bookkeepings. The results of a farm or of the regional groups can be compared to preceeding years or to conventional reference groups. Also, the

Table 3. Criteria used to evaluate performance and feasibility of IFS pilot farms.

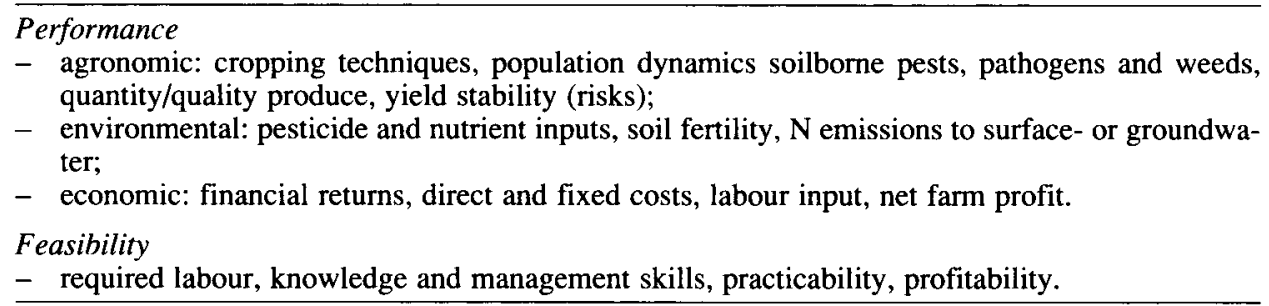


relative performance of a farm within the group can be established to consider the influence of the management factor. The region-specific potential for integration of economic and environmental goals and corresponding farming systems is being investigated by the Centre for Agrobiological Research in Wageningen using multiple-goal linear programming techniques (Schans, 1991). A set of farming systems ranging from low input to high input is generated with a computer model by systematic variation of major crop management components within a defined environment. The data sets collected on the pilot farms are used for validation of the model. The generated farming systems are optimized with respect to economic and environmental goals at several integration levels under region-specific constraints. The farming systems thus selected indicate the difference between actual and optimal performance of pilot farms at the desired integration level of economic and environmental goals. These optimized systems can then serve as a guideline for the research on and implementation of IFS

Concerning the feasibility (Table 3), the initial dialogue between the extension specialist and the farmer already provides detailed insight into what the farmer thinks is feasible on his farm and which constraints have to be faced. These constraints are documented in the reports of the extension specialists. The change of constraints over time is followed as well as the factors that influence this. All bettlenecks and constraints are classified in different categories (Table 3) and related to the agronomical demands for participation in the project (Table 2) and thus provide a good insight into the soil, farm and manager influence when implementing IFS. Through detailed study of the results reached so far and the constraints experienced, research priorities can be identified.

\section{Introduction of IFS in the farming community}

The large-scale introduction of IFS can only be successful if the farming community (farmers, advisors, teachers, etc.) is sufficiently motivated for and, preferably by practical experience, familiar with (elements of) IFS. The major activity of this part of the project is to offer as many farmers as possible the opportunity to build up experience with IFS. Therefore a network of study groups is started (Table 1, Figure 1). The registration of relevant technical data provides a reference base for mutual exchange and evaluation and reveals weak points in the curent management. Subsequently, management programmes are made for the next growing season. These mostly are limited to single crops, with the extension officer in an advising and supporting role. Finally, the results are evaluated and discussed in each group and reported to the coordinator (Table 1). The study group farmers can learn from other pilot farms in the same region, directly by means of visits and exchange and indirectly through the extension officer.

Other activities concern the organization of seminars and meetings for representatives of the farming industry, so as to transfer knowledge, results and stimulate discussions on IFS. The discussion on IFS within the agricultural extension service is guaranteed by the specialized extension officers who are supporting the pilot farms. IFS is highlighted on numerous farmers meetings and in publications in farmers 
journals and research reports. This part of the project enables an evaluation of the interest in and adoption of IFS in the farming community and helps to identify constraints for general introduction of IFS.

Training and education. The objective of this supporting part of the project is to create an infrastructure of knowledge on IFS within the organisations that educate, train or advise farmers (Agricultural Extension Service, private entreprises and agricultural schools or training centres) by systematic transfer of knowledge on and training in IFS. Table 4 gives an overview of the training courses that have been initiated until now. The training activities started in 1988/1989 with the presentation of the IFS substrategies (Vereijken \& Wijnands, 1990) to all arable extension officers in the Netherlands. This was followed by a long training course in the context of an EC programme called ETIC (Education and Training in Integrated Crop Protection). The central theme of the course was the elaboration of IFS substrategies into farm- and region-specific conversion plans for existing farms. A similar course setup was adopted by the Organization for Agricultural Training (STOAS). By the end of 1992 nearly $50 \%$ of all arable extension officers will have participated in one of these training courses.

In several parts of the Netherlands agricultural schools are organizing winter courses on IFS for farmers. IFS is also increasingly integrated into the curriculum of agricultural schools and into application courses for extension officers.

Table 4. Training courses on IFS in the Netherlands.

\begin{tabular}{llllll}
\hline Period & Organized by & $\begin{array}{l}\text { Number of } \\
\text { courses }\end{array}$ & $\begin{array}{l}\text { Number of } \\
\text { participants }\end{array}$ & $\begin{array}{l}\text { Length } \\
\text { (days) }\end{array}$ & $\begin{array}{l}\text { Target } \\
\text { group }\end{array}$ \\
$88 / 89$ & IKCAGV-PAGV & 1 & $80(4 \times 20)$ & $2(2 \times 1)$ & AES \\
$89 / 90$ & IKCAGV-PAGV & 1 (ETIC) & 20 & 18 & AES/teachers \\
$90 / 91$ & STOAS-IKCAGV & 2 & 40 & 18 & AES/teachers \\
$91 / 92$ & STOAS-IKCAGV & 1 & 20 & 18 & AES/teachers \\
91 & PHLO' $^{1}$ & 1 & 30 & 3 & 'open' \\
\hline
\end{tabular}

${ }^{1}$ PHLO = International Training Centre (Post-graduate).

\section{Preliminary results}

\section{Pilot farms; performance, feasibility and constraints}

Since the project started only two years ago, only preliminary results on a limited number of aspects are available. A full evaluation is only possible after the project has finished.

Agronomical state of the art. A farm-specific, multi-functionate crop rotation was established when necessary, mostly by small adaptations of the current crop rotation. Subsequently, the integrated nutrient management strategy was carefully planned over crops, fields and years (Vereijken, 1990). The $\mathrm{N}$ input was gradually decreased to offer farmers the possibility of gaining confidence in the followed approach. In 


\section{F.G. WIJNANDS}

integrated crop protection some constraints occurred, such as the (re)introduction of mechanical weed control in potato and cereals. Also the adoption of a consistent strategy to reduce fungicide use for the control of potato blight (Phytophthora infestans), appeared to be a difficult point. This especially applies to the so much required adaptions in cultivar choice, which mostly means replacing the very disease-sensitive cultivar Bintje. Agronomically the adoption of IFS seems to be well on its way. However, large regional differences occur in extent and speed of the adoption of new techniques. The objectives set for the two remaining years of the project (1992-1993) are: stabilizing the results reached so far; specifying the IFS strategies regionally; minimizing non-farm specific variations in the techniques and methods used and optimizing the adoption of IFS in general.

Pesticide use and costs. In 1991, the total use of pesticides (kg a.i. ha $\left.{ }^{-1}\right)$ on the pilot farms was on average reduced by $36 \%$, compared to 1987-1989 (Table 5). For herbicides, fungicides, insecticides and growth regulators these reductions amount to $53,23,66$ and $0 \%$ respectively. For herbicides, the reduction varies from $41 \%$ on the Southwestern Clay to $68 \%$ on the Central Clay. These reductions are based on mechanical control techniques and band spraying and lead to direct cost savings varying from NLG 70-130 per hectare. The reduction in the use of other pesticides, based on the adoption of the integrated crop protection strategy, varies from $18 \%$ on the Central Clay to $51 \%$ on the Southeastern Sand and reduces direct costs by NLG 60-125 per hectare. Nematicide use is excluded from the active ingredient figures because proper evaluation is only possible after the data of 1992 and 1993 have been collected.

Fertilizer use and costs. The $\mathrm{P}$ input on the participating farms over 1987-1989 is considered as unnecessarily high related to the soil fertility status of the soils (Table 5). As a result, the adoption of the integrated nutrient management strategy leads to

Table 5. Annual inputs of pesticides $\left(\mathrm{kg} \mathrm{ha}^{-1}\right.$ a.i.) and nutrients $\left(\mathrm{kg} \mathrm{ha}^{-1}\right)$ per farm for each region; savings in direct pesticide and fertilizer costs (NLG ha ${ }^{-1}$ ) in comparison to average costs over the years 1987-1989 (legends, see Figure 1; national figures are averaged over all participating farms).

\begin{tabular}{|c|c|c|c|c|c|c|c|c|c|c|c|c|c|c|c|c|c|c|}
\hline & \multicolumn{3}{|l|}{$\mathrm{NC}$} & \multicolumn{3}{|l|}{$\mathrm{CC}$} & \multicolumn{3}{|l|}{ SWC } & \multicolumn{3}{|l|}{ NES } & \multicolumn{3}{|l|}{ SES } & \multicolumn{3}{|c|}{ National } \\
\hline & $87 / 89$ & 90 & 91 & $87 / 89$ & 90 & 91 & $87 / 89$ & 90 & 91 & $87 / 89$ & 90 & 91 & $87 / 89$ & 90 & 91 & $87 / 89$ & 90 & 91 \\
\hline \multicolumn{19}{|l|}{ Inputs ( $\left.\mathrm{kg} \mathrm{ha}^{-1}\right)$} \\
\hline - herbicides & 3.2 & 2.7 & 1.8 & 3.7 & 2.0 & 1.2 & 4.1 & 2.8 & 2.4 & 2.8 & 1.6 & 1.6 & 2.2 & 1.2 & 0.8 & 3.2 & 2.0 & 1.5 \\
\hline - fungicides & 4.5 & 4.0 & 3.1 & 6 & 4.9 & 4.6 & 4.1 & 3.8 & 3.2 & 4.1 & 4.3 & 4.0 & 5.0 & 3.9 & 2.9 & 4.7 & 4.2 & 3.6 \\
\hline - insecticides & 0.3 & 0.2 & 0.1 & 0.3 & 0.3 & 0.1 & 0.3 & 0.2 & 0.1 & 0.1 & 0.2 & 0.1 & 0.2 & 0.1 & 0.1 & 0.3 & 0.2 & 0.1 \\
\hline - growth regulators & 0.1 & 0.1 & 0.0 & 0.2 & 0.3 & 0.3 & 0.2 & 0.2 & 0.1 & 0.0 & 0.0 & 0.0 & 0.1 & 0.0 & 0.0 & 0.1 & 0.1 & 0.1 \\
\hline- total & 8.1 & 7.0 & 5.0 & 9.8 & 7.5 & 6.2 & 8.7 & 7.0 & 5.8 & 7.0 & 6.1 & 5.7 & 7.5 & 5.2 & 3.9 & 8.3 & 6.6 & 5.3 \\
\hline$-N$ & 215 & 180 & 175 & 200 & 160 & 170 & 240 & 210 & 225 & 215 & 195 & 195 & 300 & 200 & 190 & 235 & 190 & 190 \\
\hline$-P$ & 45 & 40 & 35 & 55 & 35 & 35 & 45 & 35 & 30 & 60 & 35 & 35 & 70 & 40 & 40 & 55 & 40 & 35 \\
\hline$-\mathrm{K}$ & 120 & 110 & 125 & 95 & 100 & 110 & 120 & 125 & 125 & 165 & 145 & 130 & 230 & 140 & 145 & 145 & 125 & 125 \\
\hline \multicolumn{19}{|l|}{ Savings (NLG ha-1) } \\
\hline - fertilizers & & 50 & 30 & & 65 & 50 & & 75 & 80 & & 125 & 125 & & 80 & 80 & & 80 & 70 \\
\hline - herbicides & & 30 & 90 & & 70 & 115 & & 55 & 70 & & 155 & 130 & & 60 & 125 & & 75 & 105 \\
\hline - other pesticides & & -20 & 65 & & 80 & 60 & & 80 & 100 & & 150 & 105 & & 85 & 125 & & 75 & 90 \\
\hline- total & & 60 & 185 & & 215 & 225 & & 210 & 250 & & 430 & 360 & & 225 & 330 & & 230 & 265 \\
\hline
\end{tabular}


reductions in $\mathrm{P}$ use, varying from $10 \mathrm{~kg} \mathrm{Pha}^{-1}$ to $30 \mathrm{~kg} \mathrm{Pha}^{-1}$. The largest reductions in $\mathrm{P}$ use appear in the two sandy regions where organic manure use often passes the stage of agronomical sound practices. Over the years the use of $\mathrm{K}$ stays about the same, again with exception of the two sandy regions. Mineral fertilizers are substantially replaced by organic manure. The $\mathrm{P}$ use as mineral fertilizer amounts in all regions to only about $5 \mathrm{~kg} \mathrm{P} \mathrm{ha}^{-1}$. Generally this substitution results in an increased input of $\mathrm{N}$. However, as a result of the moderated $\mathrm{N}$ fertilization per crop, the total $\mathrm{N}$ input decreases on average by $45 \mathrm{~kg} \mathrm{~N} \mathrm{ha}^{-1}$, varying from $15 \mathrm{~kg}$ ha to $110 \mathrm{~kg} \mathrm{ha}^{-1}$. The direct costs of fertilizer use are reduced by NLG 30-125 per hectare. It is too early to report on the $\mathrm{N}$ emission assesments as the data of 1992 and 1993 first have to be available.

Economic aspects. The achieved savings in direct fertilizer and pesticide costs create the required financial means to compensate for increased labour demand, to invest in new machinery and to compensate for possible lower financial returns (Table 5). Comparisons with conventional reference groups and analyses over time (trends) can be very helpful here. The economic analyses have been started only recently, since full economic bookkeeping is only available about one year after harvest. In 1990, the savings in direct fertilizer and pesticide costs vary from NLG 60 to NLG 430 per hectare and in 1991 from NLG 185 to NLG 360 per hectare. The participating farmers are satisfied with the fact that their harvest (physical quantity and quality) did not fall short of their expectations. However, detailed analyses will have to prove the economic feasibility of IFS.

Feasibility. For IFS the management quality is perhaps even more important than for conventional farming, since IFS requires: (1) careful planning of activities on farm, field and crop level; (2) flexible field- and year-specific management of inputs and interventions; (3) sufficient expertise concerning the monitoring and control of weeds, pests and diseases and the use of the necessary machines and equipment. Most of the participants are enthousiastic about their increased awareness of the total farm production process, especially with respect to the quantitative aspects of the pesticide and fertilizer use. All farmers signal an increased labour demand for their total farm management and operations. Apart from the amount of time required for learning, some of this extra time may be structural, especially with respect to planning and management tasks and field operations. The extent of this effect can only be evaluated after some years. Probably more sustainable farming requires a greater commitment and expertise on the part of the farmers.

The expertise needed for adopting IFS techniques under a range of varying farm, soil and weather conditions, is at present not always available, inherent to the character of a pilot farm project. However, the collective pool of practical experience is rapidly increasing. The required management skills can only be learned by practical experience. By increasing their knowledge and practical experience, farmers gain confidence in the IFS approach, which reduces the initial risk feeling inherent to the adoption of new technology and new cropping strategies. Finally, this risk feeling is also related to the profitability of IFS. It is striking how little farmers are aware of 


\section{F.G. WIJNANDS}

the extent to which their direct costs are reduced. When these economic figures become available to them, farmers gain confidence in this respect, too.

\section{Introduction of IFS: interest, adoption and constraints}

Until now, the study group approach has had little success. Only a few groups are still functioning well and the total number of participants is disappointing. The high demands for participation (registration, planning) might have been to high a threshold. Also the link to the pilot farms in the region is probably too weak to ensure a positive impetus on the study groups.

There are a number of other, general aspects that limit the willingness of farmers to adopt IFS. Since IFS offers no financial bonus, adoption is strongly dependant on the farmers' motivation to integrate environmental objectives in his farm management. This motivation appears to be limited in the farming community. IFS is often negatively associated with political issues concerning the crop protection policy. Also the limited amount of published material on practical aspects of IFS and the low degree of practical expertise in the farming community plays a role. All these aspects hamper the adoption of IFS by farmers. Important is also the role of the Agricultural Extension Service. This organization appears to be insufficiently committed to disseminate IFS, despite the fact that as much as $50 \%$ of the arable extension officers has or is participating in training courses on IFS. Until now, little of this knowledge is integrated in the daily work of the extension officers. Finally, there are, of course, partly conflicting interests between the objectives that IFS is pursuing and industrial concerns.

\section{Perspectives and constraints}

Integrated farming is a major tool to realize the environmental policy targets of the government in the Netherlands. Therefore the current project has been set up to evaluate and introduce IFS in the farming community. The IFS prototypes are tested on a rather large scale on commercial pilot farms. The experiences until now demonstrate that IFS demands a farm-specific approach. The adoption of IFS on the pilot farms is well on its way, however, with large regional differences in extent and speed. Major constraints until now appear to be the integrated cropping strategy for potato and to some extent the reintroduction of mechanical weed control. The influence of varying soil and management conditios is becoming apparent, which will enable the composition of region-specific, safe and generally applicable variants of IFS. The quantative effects of implementation of IFS in terms of reduction of costs, pesticide use, nutrient emissions, etc., vary largely from farm to farm depending on starting level, farm-size, infrastructure (equipment, buildings), farming plan (crops, areas), soil type etc. On average, the pilot farms already meet the crop protection policy targets for the year 2000 (Anonymous, 1991). Concerning the $\mathrm{N}$ emissions, a full evaluation has to wait until the data of 1992 and 1993 are available.

However, it is questionable if the farming community will follow. Here, the first experiences of the study groups raise some doubts. Few farmers are motivated 
enough to adopt and test new techniques with minimal support. Moreover, the Agricultural Extension Service is not supporting adequately the introduction of IFS. Until now, lack of motivation (at the individual and organizational level) and practical experience seem to have been the major constraints. These problems may be overcome in the coming years. In order to reanimate the study groups, it is considered necessary to strengthen their relation to the pilot farms.

It might have been better to delay the study group component of the project by two or three years, since the major constraint for a broader adoption of IFS by farmers and the extension service seems to be the lack of convincing practical evidence on commercial farms. Now this evidence is becoming available, the motivation to adopt IFS might get a positive stimulus. Nevertheless, it is to be doubted whether the majority of farmers are willing to integrate ecological and environmental aspects into their farm management. Restrictive legislation and regulating measures concerning use of nutrients and pesticides might be inevitable to stimulate the large scale adoption of IFS. Besides, financial impulses may enhance the farmers' motivation. Also increasing efforts have to be undertaken to get the required knowledge directly across from research to practice, through practical manuals and articles. Recently, a handbook on IFS has directly been distributed to all 18000 arable farmers in the Netherlands (Vereijken \& Wijnands, 1990). However, still quite some concerted action of research, extension and farmers will be necessary to achieve the so urgently needed adaptations of agricultural practice in the Netherlands.

\section{References}

Anonymous, 1990. Agricultural Structure Memorandum. Government decision. (In Dutch). Ministry of Agriculture, Nature Management and Fisheries. SDU, The Hague. (Essentials available in English).

Anonymous, 1991. Multi-Year Crop Protection Plan. Government decision. (In Dutch). Ministry of Agriculture, Nature Management and Fisheries. SDU, The Hague. (Essentials available in English).

Schans, J., 1991. Optimal potato production systems with respect to economic and ecological goals. Agricultural Systems 37: 387-397.

Vereijken, P., 1989a. From integrated control to integrated farming, an experimental approach. Agriculture, Ecosystems and Environment 26: 37-43.

Vereijken, P., 1989b. Experimental systems of integrated and organic wheat production. Agricultural Systems 30: 187-197.

Vereijken, P., 1990. Integrated nutrient management for arable farming. La Recherche Agronomique en Suisse 29: 359-365. (Also in German, p. 367-371)

Vereijken, P., 1992. A methodic way to more sustainable farming systems. Netherlands Journal of Agricultural Science 40: 209-223.

Vereijken, P. \& C.D. van Loon, 1991. A strategy for integrated low-input potato production. Potato Research 34: 57-66.

Vereijken, P. \& F.G. Wijnands, 1990. Integrated agriculture into practice; strategy for farm and environment. (In Dutch). Publication No. 50, Research Station for Arable Farming and Field Production of Vegetables, Lelystad, $85 \mathrm{pp}$.

Wijnands, F.G. \& P. Vereijken, 1989. Environmental and economic aspects of integrated sugar beet cropping on an experimental farm. Proceedings of the 52nd Winter Congress IIRB: 119-129.

Wijnands, F.G. \& P. Vereijken, 1992. Region-wise development of prototypes of integrated arable farming and outdoor horticulture. Netherlands Journal of Agricultural Science 40: 225-238. 